\title{
PESQUISA DE IgG NEGATIVA EM PACIENTE INFECTADA PELO SARS-CoV-2
}

\author{
RESERCH ON NON-DETECTED PERMANENT IMMUNITY OF \\ A PATIENT INFECTED BY SARS-CoV-2
}

\author{
Maria Tavares Pereira Monteiro' ${ }^{1}$, Letícia Cardoso Rodrigues Pinto ${ }^{1}$, Pedro Augusto da Silva Pereira ${ }^{1}$, Raphaella \\ Santos Schwartz' ${ }^{1}$, Laura Paes Moraes ${ }^{1}$, Sheila Tavares Pereira ${ }^{2}$ \\ ${ }^{1}$ Acadêmico de Medicina da Faculdade de Medicina de Campos. \\ 2 Doutora em biociências e biotecnologia. \\ Faculdade de Medicina de Campos. Av. Alberto Torres, 217 - Centro - Campos dos Goytacazes \\ Endereço para correspondência: \\ Maria Tavares Pereira Monteiro \\ Rua Aires de Souza, 303, Parque Rodoviário, Condomínio Parthenon - P14 - CEP 28051320, Campos dos \\ Goytacazes - RJ, Brasil. - (22) 99957-0822 - maria_tavares_monteiro@hotmail.com
}

\section{RESUMO}

Este relato de caso propõe-se a abordar alguns fatores influentes sobre o monitoramento da COVID-19 e a contenção dos novos casos a partir da análise da resposta imunológica e do desenvolvimento de anticorpos. Sob essa perspectiva, reporta-se um caso de infecção pelo SARS-CoV-2 em que o paciente apresentou, na sorologia, IgM reagente e IgG não-reagente em um primeiro exame e, após 17 dias, uma nova testagem relatou IgM e IgG não-reagentes. A partir deste relato em questão, esse estudo visa ponderar sobre algumas circunstâncias no contexto da doença, como as suas fases e a consolidação da imunidade. Assim sendo, evidenciou-se a discussão sobre as cascatas e as janelas imunológicas a partir de pesquisas relacionadas a indivíduos sintomáticos e assintomáticos, correlacionando os aspectos de possíveis reinfecções. Por conseguinte, dados científicos foram averiguados para avaliar a eficiência dos métodos de detecção da doença, bem como a sua precisão, de acordo com os diferentes contextos em que os indivíduos acometidos pela infecção se encontram.

Palavras chave: COVID-19, Relato, Resposta Imunológica, Imunidade, Métodos de Detecção.

\section{ABSTRACT}

This case report proposes to address some influential factors on the monitoring of COVID-19 and the containment of new cases from the analysis of the immune response and antibody development. From this perspective, a case of SARSCoV-2 infection is reported in which the patient presented, in serology, IgM reagent and IgG nonreagent in a first examination and, after 17 days, a new test reported IgM and IgG non-reagents. From this report in question, this study aims to consider some circumstances in the context of the disease, such as its phases and the consolidation of immunity. Thus, the discussion about the cascades and the immunological windows from researches related to symptomatic and asymptomatic individuals, correlating the aspects of possible reinfections, was evidenced. Therefore, scientific data were verified to evaluate the efficiency of the methods of detection of the disease, as well as their accuracy, according to the different contexts in which the individuals affected by the infection are. Keywords: COVID-19, Report, Immune Response, Immunity, Detection Methods. 


\section{INTRODUÇÃO}

O SARS-CoV-2, severe acute respiratory syndrome coronavirus 2 (síndrome respiratória aguda grave de coronavírus 2 ), causador da doença denominada COVID-19, teve origem na cidade de Wuhan, na China, sendo o primeiro caso registrado em dezembro de 20191. Enquanto, no Brasil, o primeiro caso notificado como confirmado foi na cidade de São Paulo, em 26 de fevereiro de 2020, sendo declarada transmissão comunitária em todo o território nacional em 26 de março de $2020^{2}$. A taxa de propagação cresceu diariamente com configuração exponencial, de forma a apresentar 3.804.803 casos confirmados de COVID-19 no Brasil em 28 de agosto de 2020, segundo dados das Secretarias Estaduais de Saúde.

$\mathrm{O}$ vírus SARS-CoV-2 se alastra mormente através de gotículas de saliva ou secreção nasal. Este leva a uma infecção com um quadro clínico que varia de infecções assintomáticas até quadros extremamente graves ${ }^{1}$. Sob essa ótica, é importante salientar sobre o tempo de incubação após o contágio, que pode variar de 2 a 14 dias $^{2}$. Por esse motivo, é imprescindível o cumprimento dos protocolos frente à propagação do SARS-CoV-2, visto que uma de suas características chave de potencial pandêmico trata-se da capacidade transmissória de assintomáticos. Dados da OMS (Organização Mundial da Saúde) indicam que $80 \%$ dos infectados são assintomáticos ou oligosintomaticos, $20 \%$ necessitam de atendimento hospitalar, e $5 \%$ de suporte ventilatório ${ }^{1}$.

Os sinais e sintomas iniciais da doença são semelhantes à infecção por Influenza, os quais apresentam-se como febre, tosse, fadiga e mialgias. Esses podem ser associados com rinorreia, cefaleia, hemoptise, hiposmia, anosmia e diarreia. No entanto, os sintomas clínicos referentes à evolução mais crítica da doença são dispneia, taquipneia e febre alta. O quadro ainda pode progredir para síndrome respiratória aguda grave, lesão cardíaca ou renal, infecção secundária e choque. Nota-se a prevalência da mortalidade nos idosos, principalmente acima dos 80 anos, bem como em indivíduos com comorbidades pré-existentes, como cardiopatias, hipertensão, diabetes, doenças respiratórias crônicas e neoplasias ${ }^{2}$.

O laboratório clínico é um recurso amplamente utilizado em todas as fases da infecção pelo SARS-CoV-2, uma vez que é essencial para comprovação de diagnóstico, acompanhamento e evolução da afecção no indivíduo, tal como o prognóstico da doença com suas repercussões diretas e indiretas no organismo. Em verdade, como se trata de uma infecção viral, os achados laboratoriais gerais pela infecção por COVID-19 geralmente resultam em leucocitose ou leucopenia, associada a linfopenia acentuada nos estágios iniciais da doença, bem como presença de neutrofilia, achado associado a prognóstico ruim ${ }^{2}$. Diante do pressuposto, a análise de um exame laboratorial do indivíduo com SARS-CoV-2 deve ser direcionada à procura de marcadores de infecção e, por sua vez, resultantes sistêmicas no organismo, no intuito de elucidar a abordagem mais prudente frente ao paciente.

Entre pacientes de UTI, as alterações laboratoriais características incluem linfopenia, com redução de linfócitos $\mathrm{CD} 4$ e CD8, aumento do tempo de depleção do fator II de coagulação (protrombina - PT), aumento de $L D H$, dímero-D, proteína C reativa (PCR), transaminases e citocinas (IL-2, IL-7, IL-10, GCSF, IP-10, MIP1 $\alpha$ e TGF $\alpha)^{2}$.

O diagnóstico é especialmente importante no controle epidemiológico, bem como no estudo da doença COVID-19. Nesse aspecto, os casos suspeitos são confirmados por meio dos exames laboratoriais de reação em cadeia da polimerase em tempo real (RT-PCR), teste de detecção de ácido nucleico viral, e testes imunológicos à procura de anticorpos. As características da análise sorológica pelo SARS-CoV-2 representam um papel essencial frente à interpretação dos resultados - produção de IgM e IgA contra a proteína antigênica $S$ (proteína presente na espícula viral), $\mathrm{N}$ (proteína estrutural do nucleocapsídeo helicoidal) e produção de $\lg \mathrm{G}^{2}$.

\section{OBJETIVO}

Relato de caso de uma paciente infectada pelo SARS-CoV-2, tendo na sorologia IgM reagente e IgG não-reagente no primeiro exame. 17 dias após, realizou nova testagem, sendo IgM e IgG nãoreagente.

\section{DESCRIÇÃO DO CASO}

Paciente M.B.P.O, 52 anos de idade, sexo feminino, branca, casada, apresentou quadro clinico de cefaleia e calafrios. Quatorze dias após o início dos sintomas, realizou teste sorológico para SARSCov-2 no dia 12 de junho de 2020 em um laboratório da rede particular da cidade de Campos dos Goytacazes, estado do Rio de Janeiro. A mesma não 
apresentava comorbidades pré-existentes.

No primeiro exame sorológico, realizado no dia 12 de junho de 2020, a paciente apresentou IgM reagente e IgG não reagente para SARS-CoV-2 (FIGURA 1)

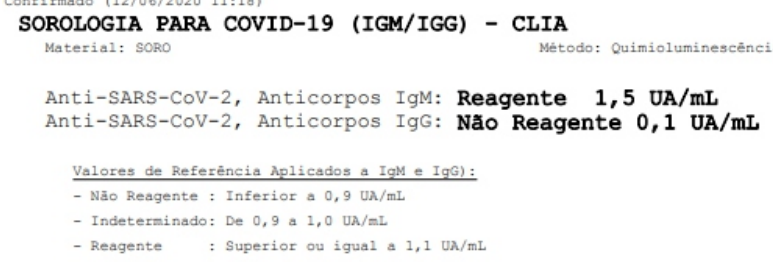

Em 29 de junho de 2020, foi realizada nova sorologia para SARS-Cov-2, na qual a paciente apresentou IgM e IgG não-reagentes para SARS-CoV2. (FIGURA 2)

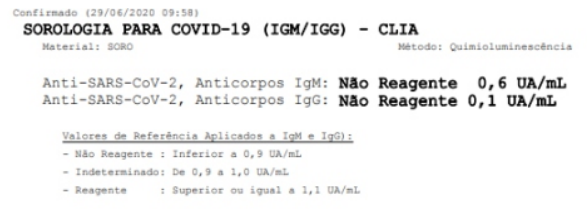

\section{DISCUSSÃO}

O conhecimento acerca dos eventos envolvidos na resposta imunológica contra o SARSCoV-2 é de grande valia para nortear estudos e pesquisas a respeito dos mecanismos de controle e eliminação do vírus, além do monitoramento da Covid-19 e contenção de novos casos ${ }^{7}$. Atualmente, não há evidências suficientemente conclusivas que indiquem imunidade ou que excluam a possibilidade de reinfecção àqueles indivíduos previamente infectados com o novo coronavírus 3. As imunoglobulinas IgM e IgG apontam diferentes fases da doença, sendo a imunoglobulina do tipo $G$ indicadora da fase crônica da doença ou indicadora de pacientes considerados curados, enquanto a imunoglobulina do tipo $\mathrm{M}$ indica a doença em sua fase aguda ${ }^{7}$. A maioria dos indivíduos infectados desenvolve anticorpos na segunda semana após a manifestação dos sintomas. Comumente, diante da exposição ao vírus, o sistema imunológico do indivíduo irá reagir ao mesmo desenvolvendo uma resposta imune que consiste na produção de anticorpos, havendo manifestação clínica ou não. 0 genótipo viral, a concentração viral, a genética do hospedeiro e a imunidade são alguns dos fatores que irão influenciar na produção dos anticorpos ${ }^{4}$. Espera-se que, em torno de 30 dias, a maior parte dos indivíduos infectados desenvolva anticorpos IgG detectáveis que confiram proteção contra uma possível reinfecção ou redução na infecciosidade; porém, devido ao avanço vertiginoso da pandemia, ainda não se sabe a durabilidade, o nível de proteção e a concentração necessária para conferir a imunização. A janela imunológica compreende o intervalo entre a exposição viral e a produção de anticorpos. Esses anticorpos devem ser produzidos em níveis detectáveis pela sensibilidade dos testes. No caso da COVID-19, os anticorpos são produzidos e detectados em média de 7 a 10 dias após a infecção.

Tal fato pode sofrer variações devido a aspectos imunológicos previamente citados, como o genótipo viral, a concentração viral, entre outros ${ }^{4},{ }^{5}$. Um estudo realizado pela School of Immunology \& Microbial Sciences promoveu a análise da ligação dos anticorpos às proteínas virais e da capacidade dos mesmos de impedir que o SARS-CoV-2 infectasse as células-alvo. Foi constatado que a concentração de anticorpos capazes de promover tais eventos atingiram o valor necessário três semanas após o início dos sintomas e, posteriormente, tiveram seus níveis circulantes na corrente sanguínea reduzidos com o decorrer do tempo após a infecção. Os níveis de anticorpos para o vírus da Covid-19 apresentaram-se em valores mais expressivos em indivíduos infectados que manifestaram a doença com um quadro clínico mais grave. Em contrapartida, também foi evidenciado que indivíduos infectados de forma assintomática sintetizaram anticorpos. Em relação a outros coronavírus, as respostas imunológicas desencadeadas por estes demonstraram declínio em um período que varia de 12 semanas a 12-34 meses após o episódio infeccioso ${ }^{6}$. Outro estudo publicado por Zhao e colaboradores observou que a detecção de IgG positivo para SARS-CoV-2 alcançou $100 \%$ de 17 a 19 dias após o surgimento dos primeiros sintomas, ao mesmo tempo que os pacientes com IgM positivo alcançaram o pico de $94,1 \%$ de 20 a 22 dias depois do primeiro sintoma. No decorrer das primeiras 3 semanas pós sintomas, relatou-se aumento de IgG e IgM para SARS-CoV-2. Neste estudo foram analisados 173 indivíduos que apresentaram janela imunológica para IgM e IgG superior a 14 dias. Cem por cento dos indivíduos foram diagnosticados com IgM positivo e anticorpos totais depois de 1 mês de infecção. Em alguns pacientes não foi possível a detecção de RNA nas amostras colhidas da nasofaringe e orofaringe. 
Exames foram feitos entre 1 a 3 dias pós-sintomas, com RNA indetectável, porém, 28,6\% apresentaram anticorpo total detectado, entre os dias 4 a $7,53,6 \%$ foram detectados, nos dias 8 a 14, 98,2\%; e nos dias 15 a 39, 100\% foram detectados. Dessa forma, é possível constatar que, utilizando método de detecção de RNA juntamente com método de detecção de anticorpos, o diagnóstico para COVID19 torna-se muito mais sensível e preciso em fases distintas ${ }^{8}$.

Sob essa ótica proposta, com a sequência de eventos imunológicos e quadro apresentado pela paciente relatada no caso, a produção de IgG deve ocorrer neste período, pois o tempo em questão seria correspondente à fase crônica da doença. No entanto, a partir do resultado apresentado no laudo da paciente em análise, observa-se que contraria o padrão da cascata imunológica e as estatísticas, que apontam que a proporção de pacientes com IgG específica para vírus tem alcance de $100 \%$ em aproximadamente 17 a 19 dias após o início dos sintomas ${ }^{4}$. A paciente, neste caso, não sintetizou o IgG ou a sua produção ocorreu em níveis indetectáveis pela metodologia, ou ainda a produção ocorreu, mas a imunidade não foi duradoura.

\section{CONCLUSÕES}

O desfecho deste artigo conclui que, em meio às evidências e descobertas que estão em processo de consolidação, é imprescindível que os diversos casos sejam relatados, de forma que as peculiaridades de cada caso sejam consideradas. A OMS necessita desses relatos para inspecionar as evidências referentes aos anticorpos da infecção por SARS-CoV-2, pois essas informações agregam novas circunstâncias que se enquadram em novas perspectivas para o conhecimento sobre a doença. Constata-se ainda que, além disso, outros aspectos como os fatores de risco associados à infecção podem ser determinados de forma mais exata por meio da exposição desses estudos. Essa contribuição impulsiona ainda mais as pesquisas e a geração de novas informações fundamentadas, que servem de base para a tomada de medidas de contenção da doença a partir de um novo paradigma que contemple novas possibilidades. Por fim, conclui-se que esses dados servem como base para novas descobertas que buscam cooperar para que essa enfermidade de repercussão pandêmica possa ser erradicada.

\section{REFERÊNCIAS BIBLIOGRÁFICAS}

1- MINISTÉRIO DA SAÚDE (Brasil). Sobre a doença: O que é COVID-19. In: MINISTÉRIO DA SAÚDE (Brasil). Sobre a doença: O que é COVID-19. [S. I.], 23 jun. 2020. Disponível em: https://coronavirus.saude.gov.br/sobre-a-doenca\#o-que-e-covid. Acesso em: 14 set. 2020.

2- XAVIER, Analucia R. et al . COVID-19: manifestações clínicas e laboratoriais na infecção pelo novo coronavírus. J. Bras. Patol. Med. Lab., Rio de Janeiro, v. 56, e3232020, 2020. DOI: 10.5935/1676-2444.20200049. Disponível em http://www.scielo.br/scielo.php?script=sci_arttext\&pid=S1676-24442020000100302\&lng=pt\&nrm=iso.Epub 01-Jul-2020. . Acesso em: 14 set. 2020.

3- ORGANIZAÇÃO MUNDIAL DE SAÚDE (América). Organização Pan-Americana de Saúde. Folha informativa COVID-19 Escritório da OPAS e da OMS no Brasil: Principais informações. In: Folha informativa COVID-19 - Escritório da OPAS e da OMS no Brasil: Principais informações. Paho, 14 set. 2020. Disponível em: https://www.paho.org/pt/covid19. Acesso em: 14 set. 2020.

4- DIAS, Viviane Maria de Carvalho Hessel et al. Testes Sorológicos para COVID-19: Interpretação e Aplicações Práticas. Journal of Infection Control, SBN, 16 jun. 2020. Disponível em:

https://www.sbn.org.br/fileadmin/user_upload/Noticias/Artigo_de_Revisao_para_Journal_of_Infection_Control.pdf. Acesso em: 14 set. 2020.

5- CENTERS FOR DISEASES CONTROL AND PREVENTION. Interim Guidelines for COVID-19 Antibody Testing: Interim Guidelines for COVID-19 Antibody Testing in Clinical and Public Health Settings. In: Interim Guidelines for COVID-19 Antibody Testing: Interim Guidelines for COVID-19 Antibody Testing in Clinical and Public Health Settings. CDC, 1 ago. 2020. Disponível em: https://www.cdc.gov/coronavirus/2019-ncov/lab/resources/antibody-tests-guidelines.html. Acesso em: 14 set. 2020.

6- SEOW, Jeffrey et al. Longitudinal evaluation and decline of antibody responses in SARS-CoV-2 infection. BioRxiv, medRxiv, 11 jul. 2020. DOI: 10.1101/2020.07.09.20148429. Disponível em: 
https://www.medrxiv.org/content/10.1101/2020.07.09.20148429v1\#disqus_thread. Acesso em: 22 set. 2020. 7- SINHA, NEERAJ; BALAYLA, GALIT. Bateria sequencial de testes para COVID-19 para maximizar o valor preditivo negativo antes de operações. Rev. Col. Bras. Cir., Rio de Janeiro, v. 47, e20202634, 2020. Epub 10-Jul-2020. DOI: 10.1590/01006991e-20202634. Disponível em: http://www.scielo.br/scielo.php?script=sci_arttext\&pid=S010069912020000100310\&lng=pt\&nrm=iso. Acesso em: 14 set. 2020.

8- ZHAO, Juanjuan et al. Antibody responses to SARS-CoV-2 in patients of novel coronavirus disease 2019. National Center for Biotechnology Information, PubMed, 28 mar. 2020. DOI: 10.1093 / cid / ciaa344. Disponível em:

https://academic.oup.com/cid/advance-article/doi/10.1093/cid/ciaa344/5812996. Acesso em: 22 set. 2020. 